\title{
COVID-19 Cases from the First Local Outbreak of the SARS-CoV-2 B.1.1.7 Variant in China May Present More Serious Clinical Features: A Prospective, Comparative Cohort Study
}

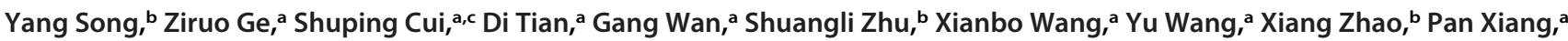

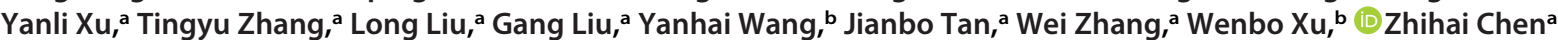 \\ aEmergency Department of COVID-19, Beijing Ditan Hospital, Capital Medical University, Beijing, China \\ bNational Institute for Viral Disease Control and Prevention, Chinese Center for Disease Control and Prevention, Beijing, China \\ cPeking University, Ditan Teaching Hospital, Beijing, China
}

Yang Song, Ziruo Ge, and Shuping Cui contributed equally to this article. The author order was determined by their equal but gradated contributions for this paper. Zhihai Chen, Wenbo Xu, and Wei Zhang contributed equally to this article. The order was determined by the corresponding author after negotiation.

ABSTRACT The SARS-CoV-2 B.1.1.7 variant has increased sharply in numbers worldwide and is reported to be more contagious than the nonvariant. Little is known regarding the detailed clinical features of B.1.1.7 variant infection. Data on 74 COVID-19 cases from two outbreaks in two districts of Beijing, China were extracted from a cloud database, including 41 cases from Shunyi District (Shunyi B.1.470 group) and 33 from Daxing (Daxing B.1.1.7 group) from December 25, 2020 to January 17, 2021. We conducted a comparison of the clinical characteristics. Seven clinical indicators of the Daxing B.1.1.7 group were significantly higher than those of the Shunyi group, including the proportion with fever over $38^{\circ} \mathrm{C}$, the levels of C-reactive protein (CRP), serum amyloid A (SAA), creatine kinase $(\mathrm{CK})$, D-dimer (DD), and $\mathrm{CD} 4^{+} \mathrm{T}$ lymphocytes $\left(\mathrm{CD} 4^{+} \mathrm{T}\right)$, and the proportion with groundglass opacity (GGO) in the lung ( $P$ values of $\leq 0.05)$. After adjusting for age, B.1.1.7 variant infection was a risk factor for elevated CRP $(P=0.045)$, SAA $(P=0.011)$, CK $(P=0.034)$, and $\mathrm{CD}^{+} \mathrm{T}(P=0.029)$ and for the presence of GGO $(P=0.005)$. The median threshold cycle $\left(C_{T}\right)$ value of reverse transcriptase quantitative PCR (RT-qPCR) tests of the $\mathrm{N}$ gene target in the Daxing B.1.1.7 group was significantly lower $(P=0.036)$ than that in the Shunyi B.1.470 group. Clinical features, including a more serious inflammatory response, pneumonia, and a possibly higher viral load, were detected in the cases infected with B.1.1.7 SARS-CoV-2. The B.1.1.7 variant may have increased pathogenicity.

IMPORTANCE The SARS-CoV-2 B.1.1.7 variant, which was first identified in the United Kingdom, has increased sharply in numbers worldwide and was reported to be more contagious than the nonvariant. To our knowledge, no studies investigating the detailed clinical features of COVID-19 cases infected with the B.1.1.7 variant have been published. Local epidemics have rarely occurred in China, but occasionally, a small clustered outbreak triggered by an imported SARS-CoV-2 strain with only one chain of transmission could happen. From late 2020 to early 2021, two clustered COVID-19 outbreaks occurred in Beijing, one of which was caused by the B.1.1.7 variant. The COVID-19 patients from the two outbreaks received similar clinical tests, diagnoses, and treatments. We found that the B.1.1.7 variant infection could lead to a more serious inflammatory response, acute response process, more severe pneumonia, and probably higher viral loads. This therefore implies that the B.1.1.7 variant may have increased pathogenicity.

KEYWORDS whole-genome analysis, B.1.1.7 variant, COVID-19, SARS-CoV-2, clinical features
Citation Song Y, Ge Z, Cui S, Tian D, Wan G, Zhu S, Wang $X$, Wang $Y$, Zhao $X$, Xiang $P$, Xu Y Zhang T, Liu L, Liu G, Wang Y, Tan J, Zhang W, Xu W, Chen Z. 2021. COVID-19 cases from the first local outbreak of the SARS-CoV-2 B.1.1.7 variant in China may present more serious clinical features: a prospective, comparative cohort study. Microbiol Spectr 9:e00273-21. https://doi.org/10.1128/Spectrum.00273-21. Editor Rosemary C. She, Keck School of Medicine of the University of Southern California

Copyright $\odot 2021$ Song et al. This is an openaccess article distributed under the terms of the Creative Commons Attribution 4.0 International license.

Address correspondence to Wei Zhang, snowpine12@sina.com, Wenbo Xu, xuwb@ivdc.chinacdc.cn, or Zhihai Chen, chenzhihai0001@126.com.

Received 16 May 2021

Accepted 28 June 2021

Published 4 August 2021 
ince December 2019, the coronavirus disease-19 (COVID-19) pandemic caused by the highly infectious virus severe acute respiratory syndrome coronavirus-2 (SARSCoV-2) has been rapidly spreading, which has posed a great threat to global public health $(1,2)$. With the continuous transmission and mutation of SARS-CoV-2, some viral variants of concern (VOCs) have been reported in recent months (3-8). On December 14, 2020, the United Kingdom reported a SARS-CoV-2 VOC that belonged to the PANGO lineage B.1.1.7 (9, 10), referred to as SARS-CoV-2 VOC-202012/01, B.1.1.7, 501Y. V1, or 20I/501Y.V1 (B.1.1.7 hereafter). The B.1.1.7 variant was estimated to have emerged in late September 2020 and has increased sharply to become the predominant SARS-CoV-2 strain in England, and it quickly became a global concern $(7,11,12)$.

With the strict prevention and control policies implemented in China, local epidemics have rarely occurred in Beijing. Occasionally, a small clustered outbreak triggered by an imported SARS-CoV-2 strain with only one chain of transmission could happen. On Jan 17, 2021, a clustered COVID-19 outbreak in the community took place in Daxing District, Beijing. Confirmed by whole-genome sequencing and lineage typing results $(9,10)$, this outbreak was caused by SARS-CoV-2 B.1.1.7. This was the first local transmission of B.1.1.7 in China, which constituted a new challenge to the prevention and control of COVID-19 in China. Three weeks prior to the Daxing outbreak, another local COVID-19 outbreak occurred in Shunyi District, Beijing, caused by the lineage B.1.470 $(9,10)$, which was detected mostly in Asian countries. Both outbreaks were well controlled within a month.

Since the early transmission of COVID-19 in January 2020, a cohort of COVID-19 cases has been established in Beijing Ditan Hospital; since June 2020, the COVID-19 cases in Beijing have been admitted only to Ditan Hospital, after which a cloud database was established and maintained by Ditan Hospital in cooperation with a Beijing technology company (Beijing Zechuang Tiancheng Technology Development Co., Ltd.). All relevant data for COVID-19 cases are constantly being entered into the cloud database to prepare for future prospective studies. So far, the data of approximately 697 cases have been input completely. In this study, groups of two recent independent clustered outbreaks caused by distinct lineage strains and occurring in different districts in Beijing (Daxing B.1.1.7 group and Shunyi B.1.470 group) were selected as the study subjects from the cloud database. The COVID-19 cases from the two groups received similar clinical tests and treatments, and each case was observed for at least 28 days.

This study aimed to compare the clinical presentations, reverse transcriptase quantitative PCR (RT-qPCR) results, and whole-genomic features of cases from the Daxing B.1.1.7 group and Shunyi B.1.470 group to evaluate the COVID-19 severity of cases infected by the B.1.1.7 variant.

\section{RESULTS}

Whole-genome sequencing and analysis of SARS-CoV-2 samples in the two outbreaks. Clinical samples from 8 patients of the Daxing outbreak and 13 patients of the Shunyi Outbreak were sent to the Chinese CDC for further sequencing. Some samples may be degraded due to transportation or storage. Finally, a total of 9 whole-genome sequences with a genome coverage over $98 \%$ were obtained, including 7 from the Daxing outbreak and 2 from the Shunyi outbreak. Compared with the Wuhan reference sequence (EPI_ISL_402119), seven Daxing strains shared 31 nucleotide substitutions, six strains were identical, and one strain had an additional substitution (32 substitutions) (Table 1). These seven strains shared all 28 nucleotide mutations that were first detected in the B.1.1.7 variant from the United Kingdom (Fig. 1).

The two strains of the Shunyi outbreak shared 24 nucleotide substitutions, and one of them had an additional substitution (Table 1), which contained the single-nucleotide polymorphisms (SNPs) defining the PANGO lineage B.1.470 confirmed by the Pangolin COVID-19 Lineage Assigner web application $(9,10)$ (https://pangolin.cog-uk .io/). This lineage is composed of only one hundred more sequences in the GISAID database, most of which (77.0\%) were from Indonesia. Strains from the GISAID database (13) that had high homology with these 2 strains were retrieved, including a Singaporean and an Indonesian strain (Fig. 1). 
TABLE 1 Comparison of the whole-genome features between the two groups

\begin{tabular}{|c|c|c|}
\hline Feature & Data for Daxing B.1.1.7 group & Data for Shunyi B.1.470 group \\
\hline No. of sequences & 7 & 2 \\
\hline PANGO lineage & B.1.1.7 & B.1.470 \\
\hline VOC or not & VOC-202012/01 & Non-VOC \\
\hline No. of shared nucleotide substitutions & 31 & 24 \\
\hline $\begin{array}{l}\text { Shared nucleotide substitution sites } \\
\text { (reference strain Wuhan-Hu-1, } \\
\text { EPI_ISL_402119) }\end{array}$ & $\begin{array}{l}\text { C241T, C913T, C3037T, C3267T, C5388A, C5986T, } \\
\text { T6954C, C12036G, C12747T, C12970T, C14408T, } \\
\text { C14676T, C15279T, T16176C, A23063T, } \\
\text { C23271A, A23403G, C23604A, C23709T, } \\
\text { T24506G, G24914C, C27972T, G28048T, } \\
\text { A28111G, G28280C, A28281T, T28282A, } \\
\text { G28881A, G28882A, G28883C, C28977T }\end{array}$ & $\begin{array}{l}\text { C241T, C1454G, C3037T, T6778C, C9679T, G11291A, } \\
\text { T11296G, C14120T, C14408T, C17421T, G18315A, } \\
\text { C18687T, C18877T, C21597T, A23403G, G25563T, } \\
\text { G25855C, G26051T, C26681T, C26735T, G27870T, } \\
\text { C27903T, C28887T, C29311T }\end{array}$ \\
\hline Additional substitution site & T21991G & T20246G \\
\hline Amino acid mutations on Spike protein & $\begin{array}{l}\text { H69-V70del, Y144del, N501Y, A570D, D614G, } \\
\text { P681H, T716I, S982A, D1118H }\end{array}$ & S12F, D614G \\
\hline
\end{tabular}

Comparison of the general information and basic clinical manifestations in the two groups. Of the 33 cases from the Daxing B.1.1.7 group and the 41 cases from the Shunyi B.1.470 group (Table 1), male cases accounted for $45.50 \%$ and $61.00 \%$, respectively. The median age of the two groups (39years [interquartile range $\{\mathrm{IQR}\} 30.50$ to 62.50] versus 31 years [IQR 27.50 to 41.00]) showed a statistically significant difference $(P=0.014)$. Moderate cases accounted for the highest percentage of both groups (66.67\% versus $48.78 \%$ ). The most common symptom in both groups was fever, followed by dry cough and dry throat/pharyngeal discomfort. Of patients infected with the B.1.1.7 variant, $14(46.43 \%)$ had fever over $38^{\circ} \mathrm{C}$, a significantly higher proportion than the $9(21.95 \%)$ patients observed infected with the B.1.470 nonvariant $(P=0.015)$.

Comparison of laboratory tests, imageological diagnoses, and treatment measures. There were no significant differences in the levels of white blood cells, neutrophils, lymphocytes, platelets, alanine aminotransferase, or aspartate aminotransferase between the two groups (Table 2). However, the levels of C-reactive protein (CRP), serum amyloid A (SAA), creatine kinase (CK), and D-dimer (DD) in the Daxing B.1.1.7 group were significantly higher than those in the Shunyi B.1.470 group $(P=$ $0.005,0.003,0.040$, and 0.038 , respectively). When we excluded the 1 patient in the Daxing B.1.1.7 group and the 2 patients in the Shunyi B.1.470 group who were not tested for $T$ lymphocytes due to their young age, the abnormal proportion of $\mathrm{CD}^{+}{ }^{+}$T lymphocytes $\left(C D 4^{+} \mathrm{T}\right)$ in the Daxing B.1.1.7 group was significantly higher than that in the Shunyi B.1.470 group $(P=0.003)$. For the imaging diagnosis, there were no significant differences in the incidence of pneumonia, but ground-glass opacity (GGO) was observed significantly more often in the B.1.1.7 group $(P=0.001)$. The antibody detection results and clinical treatments were not significantly different between the two groups.

B.1.1.7 variant infection is the main risk factor for more serious COVID-19 clinical features. In order to avoid the influence of older age in the Daxing B.1.1.7 group, binary logistic regression analysis was further performed to investigate the levels of CRP ( $<7 \mathrm{mg} /$ liter or $\geq 7 \mathrm{mg} / \mathrm{liter}$ ), SAA ( $<10 \mathrm{mg} /$ liter or $\geq 10 \mathrm{mg} / \mathrm{liter})$, CK $(<150$ $\mathrm{U} /$ liter or $\geq 150 \mathrm{U} / \mathrm{liter}$ ), DD ( $<0.5 \mathrm{mg} /$ liter or $\geq 0.5 \mathrm{mg} /$ liter), $\mathrm{CD}^{+}{ }^{+} \mathrm{T}$ ( $<700 \mathrm{mg} /$ liter or $\geq 706 \mathrm{mg} /$ /iter), and GGO in the lung (Table 3). After adjusting for age, we found that the group factor (B.1.1.7 variant infection or nonvariant infection) was the main risk factor for higher CRP (odds ratio $[O R]=2.79, P=0.045)$, higher $S A A(O R=5.03, P=0.011)$, higher CK $(\mathrm{OR}=0.22, P=0.034), \mathrm{GGO}(\mathrm{OR}=5.42, P=0.005)$, and higher $\mathrm{CD}^{+} \mathrm{T}$ $(\mathrm{OR}=3.31, P=0.029)$.

Comparison of RT-qPCR threshold-crossing values between the two groups. During the hospitalization of all the patients, several RT-qPCR tests using nasopharyngeal swabs were conducted regularly based on patients' disease progression and clinical manifestations. The lowest threshold-crossing $\left(C_{T}\right)$ value of the ORF1ab and N genes of each patient was taken for comparison between the two groups (Table 4). The kits for RT-qPCR 


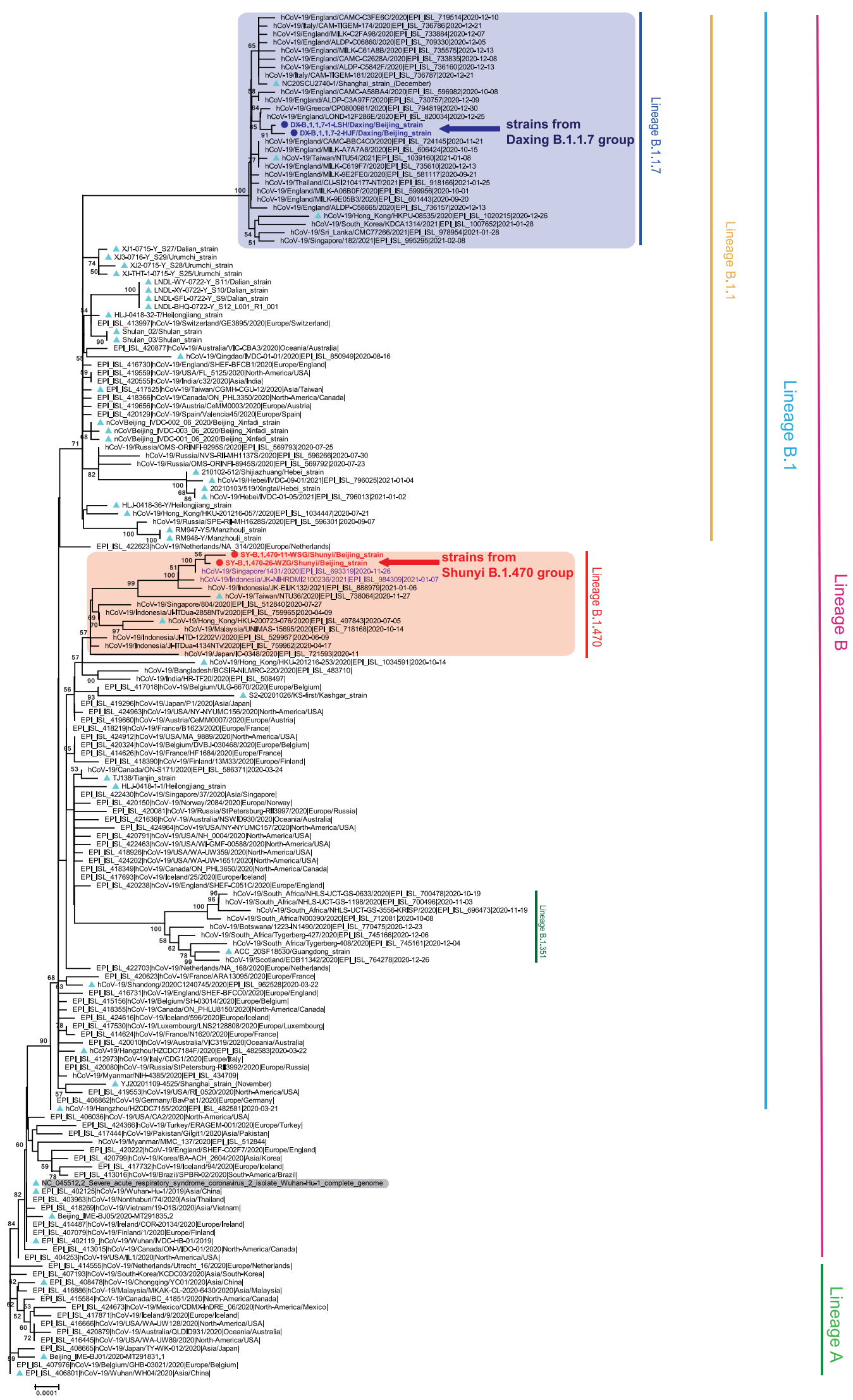

FIG 1 Neighbor-joining phylogenetic tree based on the whole-genome sequences of the SARS-CoV-2 representative strains. The two representative strains from the Daxing B.1.1.7 group are indicated by deep blue dots, deep blue font, 
TABLE 2 Comparison of the general situation and clinical manifestations

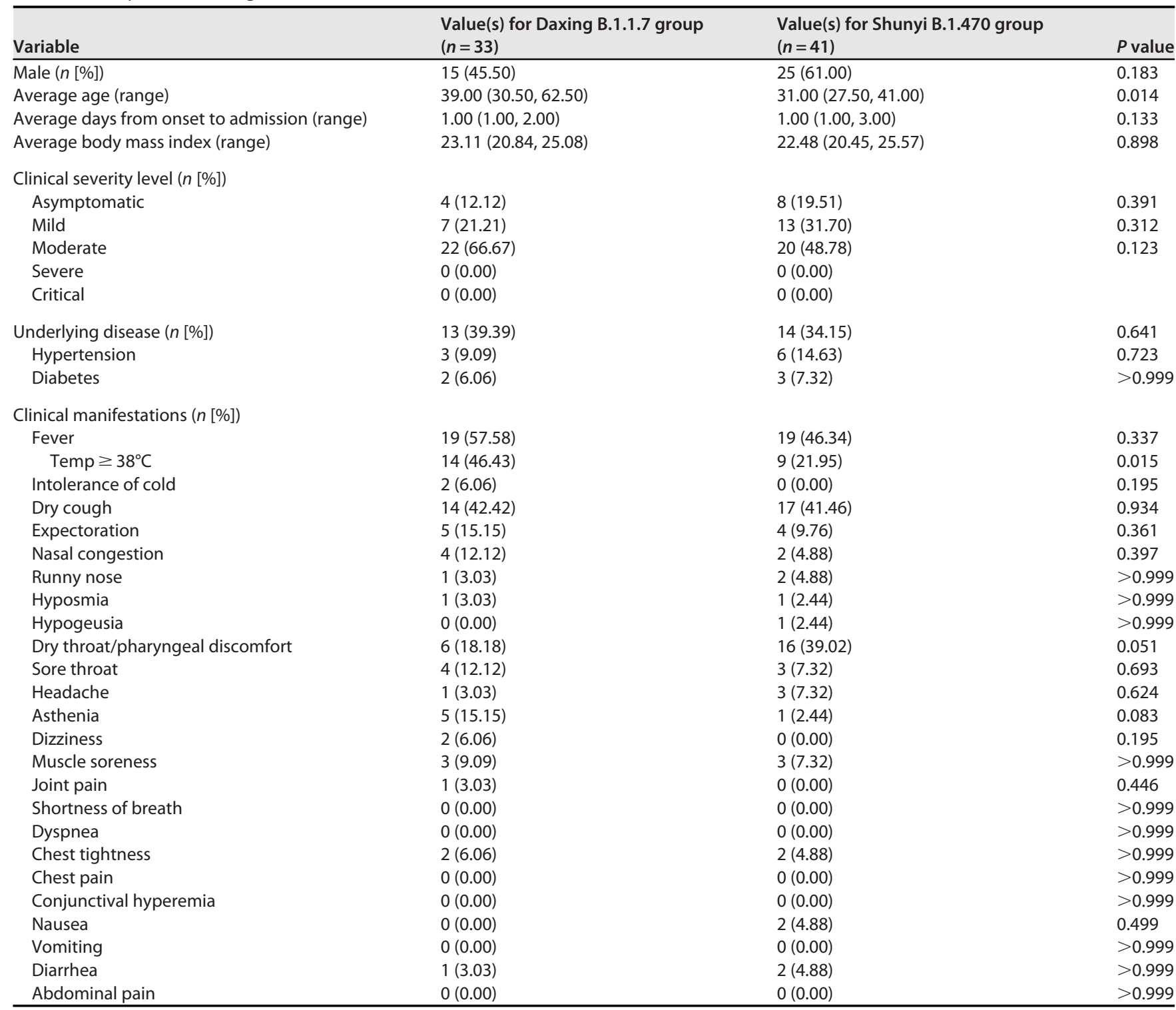

testing had the same lot numbers, and the instruments were the same. The median $C_{T}$ value of the ORF1ab gene target in the two groups was not significantly different, but that of the $\mathrm{N}$ gene target was significantly lower for the Daxing B.1.1.7 group than for the Shunyi B.1.470 group $(t=2.139, P=0.036)$. The distribution of the samples in the two groups was compared within all ORF1ab and $\mathrm{N}$ gene $C_{T}$ values (Fig. 2). Figure $2 \mathrm{~B}$ indicates that for the $\mathrm{N}$ gene, the median $C_{T}$ values of the Daxing B.1.1.7 group were higher. We also adjusted for the age factor and performed binary logistic regression analysis on the $C_{T}$ value ( $>18$ or $\leq 18$ ) (Table 5). Again, patients infected with the B.1.1.7 variant had a 4.484fold higher risk of having $\mathrm{N}$ gene $C_{T}$ values of $\leq 18$ in nasopharyngeal swab specimens than that of patients infected with nonvariants ( $O R=4.484, P=0.024)$ (Table 6).

FIG 1 Legend (Continued)

and a blue left arrow, while the strains from the Shunyi B.1.470 group are indicated by red dots, red font, and a red left arrow. Strains associated with other previous outbreaks in China are indicated with ice-blue triangles. The B.1.1.7 and B.1.470 lineages are highlighted with blue and light red backgrounds, respectively, and the two strains that shared high homology with the strains of the Shunyi B.1.470 group are colored purple. The Wuhan reference strain is shaded in gray. The PANGO lineages are marked and colored on the right. The tree was rooted using strain WH04 (EPI_ISL_406801) in accordance with the root of the Pangolin tree. 
TABLE 3 Comparison of laboratory tests, $C_{T}$ results, and treatment measures

\begin{tabular}{|c|c|c|c|}
\hline Variable & $\begin{array}{l}\text { Values for Daxing B.1.1.7 group } \\
(n=33)\end{array}$ & $\begin{array}{l}\text { Values for Shunyi B.1.470 group } \\
(n=41)\end{array}$ & $P$ value \\
\hline \multicolumn{4}{|l|}{ Laboratory tests } \\
\hline White blood cell count $\left(\times 10^{9} /\right.$ liter $)$ & $5.16(4.32,7.15)$ & $5.69(4.49,7.02)$ & 0.628 \\
\hline Neutrophil percentage (\%) & $65.30(54.42,71.25)$ & $62.30(56.90,72.96)$ & 0.786 \\
\hline Lymphocyte count ( $\times 10^{9} /$ liter $)$ & $1.42(0.93,1.91)$ & $1.39(0.91,1.82)$ & 0.996 \\
\hline Lymphocyte percentage (\%) & $23.44(19.25,34.25)$ & $27.40(18.02,35.05)$ & 0.732 \\
\hline Serum amyloid A (mg/liter) & $21.50(12.50,50.70)$ & $12.00(5.20,26.95)$ & 0.003 \\
\hline Alanine aminotransferase (U/liter) & $16.60(11.15,28.50)$ & $21.00(12.55,37.80)$ & 0.370 \\
\hline Aspartate aminotransferase (U/liter) & $26.30(18.90,34.15)$ & $23.20(17.85,29.45)$ & 0.236 \\
\hline Lactic dehydrogenase (U/liter) & $187.50(170.05,228.15)$ & $194.90(174.25,224.80)$ & 0.708 \\
\hline Creatine kinase (U/liter) & $110.50(53.15,152.40)$ & $70.40(54.35,103.05)$ & 0.040 \\
\hline Prothrombin time (s) & $12.20(11.60,12.70)$ & $12.20(11.45,12.80)$ & 0.947 \\
\hline$\geq 1027$ & $18.00(56.25)$ & $18.00(46.15)$ & \\
\hline $\mathrm{CD}^{+}{ }^{+}$T lymphocyte (cells/ $\left.\mu \mathrm{l}\right)$ & & & 0.003 \\
\hline$<706$ & $21.00(65.63)$ & $12.00(30.77)$ & \\
\hline$\geq 706$ & $11.00(34.38)$ & $27.00(69.23)$ & \\
\hline \multicolumn{4}{|l|}{$\mathrm{CD}^{+}{ }^{+}$lymphocyte (cells/ $\left.\mu \mathrm{l}\right)$} \\
\hline$<320$ & $15.00(46.88)$ & $17.00(43.60)$ & 0.782 \\
\hline$\geq 320$ & $17.00(53.13)$ & $22.00(56.41)$ & \\
\hline \multicolumn{4}{|l|}{ Imaging examination $(n,[\%])$} \\
\hline Pneumonia unilateral & $10.00(30.30)$ & $15.00(36.59)$ & 0.570 \\
\hline Pneumonia & $15.00(45.45)$ & $11.00(26.83)$ & 0.095 \\
\hline Ground-glass opacity & $15.00(45.45)$ & $5.00(12.20)$ & 0.001 \\
\hline Traditional Chinese medicine & $23.00(69.70)$ & $27.00(65.85)$ & 0.726 \\
\hline Oxygen inhalation & $5.00(15.15)$ & $8.00(19.51)$ & 0.624 \\
\hline
\end{tabular}

\section{DISCUSSION}

Numerous studies have indicated that the SARS-CoV-2 B.1.1.7 variant has transmissibility higher than that of the nonvariant, but whether it has increased pathogenicity remains controversial. In this study, we analyzed the differences in clinical characteristics, laboratory tests, RT-qPCR results, and whole-genome features between 33 patients infected with the SARS-CoV-2 B.1.1.7 variant and 41 infected with the nonvariant. The results indicated that COVID-19 patients infected with the B.1.1.7 variant had more serious clinical features and possibly higher viral loads. This implies that the B.1.1.7 variant may have increased pathogenicity.

In the Daxing B.1.1.7 group, we observed patients older than those in the Shunyi B.1.470 group, probably due to the living characteristics of residents from the community, as many retired older people were more frequently active in the community.

B.1.1.7 variant infection could lead to a more serious inflammatory response, an acute response process, and more severe pneumonia, as indicated by the following results: in the B.1.1.7 variant cases, (i) there were more fevers over $38^{\circ} \mathrm{C}$, (ii) $\mathrm{CRP}, \mathrm{SAA}$, $\mathrm{CK}$, and DD were significantly higher, (iii) an abnormal proportion of $\mathrm{CD}^{+}{ }^{+} \mathrm{T}$ was 
TABLE 4 Risk of high CRP, high SAA, and GGO by variant (B.1.1.7 variant infection or non-B.1.1.7 variant infection)

\begin{tabular}{|c|c|c|c|c|c|c|c|}
\hline Outcome & Variable & $\begin{array}{l}\text { Regression } \\
\text { coefficient }\end{array}$ & SE & $\begin{array}{l}\text { Wald Chisq } \\
\text { value }\end{array}$ & $P$ value & $\begin{array}{l}\text { Odds } \\
\text { ratio }\end{array}$ & $\begin{array}{l}95 \% \mathrm{Cl} \text { for } \\
\text { OR }\end{array}$ \\
\hline \multirow[t]{2}{*}{ Level of CRP ( $<7 \mathrm{mg} /$ liter or $\geq 7 \mathrm{mg} /$ liter) } & Age & 0.00 & 0.01 & 0.03 & 0.854 & 1.00 & $0.98,1.03$ \\
\hline & Group & 1.09 & 0.54 & 4.02 & 0.045 & 2.79 & $1.03,0.86$ \\
\hline \multirow[t]{2}{*}{ Level of SAA ( $<10 \mathrm{mg} /$ liter or $\geq 10 \mathrm{mg} /$ liter) } & Age & 0.03 & 0.02 & 2.63 & 0.105 & 1.03 & $0.99,1.06$ \\
\hline & Group & 1.62 & 0.63 & 6.54 & 0.011 & 5.03 & $1.45,17.35$ \\
\hline Had GGO or not & Age & 0.01 & 0.02 & 0.69 & 0.408 & 1.01 & $0.98,1.04$ \\
\hline \multirow[t]{2}{*}{ Level of CK ( $<150 \mathrm{U} /$ liter or $\geq 150 \mathrm{U} /$ liter) } & Age & 0.00 & 0.02 & 0.05 & 0.821 & 1.00 & $0.97,1.04$ \\
\hline & Group & -1.52 & 0.73 & 4.34 & 0.034 & 0.22 & $0.05,0.91$ \\
\hline \multirow[t]{2}{*}{ Level of DD ( $<0.5 \mathrm{mg} /$ liter or $\geq 0.5 \mathrm{mg} / \mathrm{liter})$} & Age & 0.06 & 0.03 & 6.14 & 0.013 & 1.07 & $1.01,1.12$ \\
\hline & Group & 0.70 & 0.82 & 0.73 & 0.392 & 2.01 & $0.41,10.02$ \\
\hline Level of $\mathrm{CD}^{+} \mathrm{T}(<706$ cells $/ \mu \mathrm{l}$ or $\geq 706$ cells $/ \mu \mathrm{l})$ & Age & 0.05 & 0.02 & 7.55 & 0.006 & 1.05 & $1.01,1.08$ \\
\hline
\end{tabular}

significantly more common, and (iv) ground-glass opacity in the lung was significantly more common.

Comparing the $C_{T}$ values of the RT-qPCR results between the two groups, samples from the Daxing B.1.1.7 group had lower $C_{T}$ values of the $\mathrm{N}$ gene, from which it could be speculated that B.1.1.7 variant samples may have a higher viral load. This result is in line with previous research showing that the B.1.1.7 variant is associated with significantly higher viral loads in samples tested by ThermoFisher TaqPath RT-qPCR (14). Even though the sample size in this study was relatively small and no significant difference was detected in the open reading frame (ORF) gene, the statistical results for the $\mathrm{N}$ gene could still indicate a higher infectivity of the B.1.1.7 variant.

SARS-CoV-2 B.1.1.7 variant infection may be the main risk factor for more serious clinical features after adjusting for age. Old age has been considered an important factor in SARS-CoV-2 infection and severe COVID-19 because elderly patients have weaker immune systems and are prone to multisystem organ dysfunction and even failure (15-18). Thus, we adjusted for the older age of the Daxing B.1.1.7 group and still found that cases infected with the B.1.1.7 variant presented more serious clinical features and higher infectivity.

The phylogenetic analysis showed that the strains from the two groups belonged to different lineages. The whole-genome analysis revealed that the case samples from group DX B.1.1.7 had 3 to 4 specific substitutions in addition to the 28 nucleotide substitutions corresponding to the B.1.1.7 reference sequence, which indicated that the strains might have been evolving for some time before being transmitted to China.

A

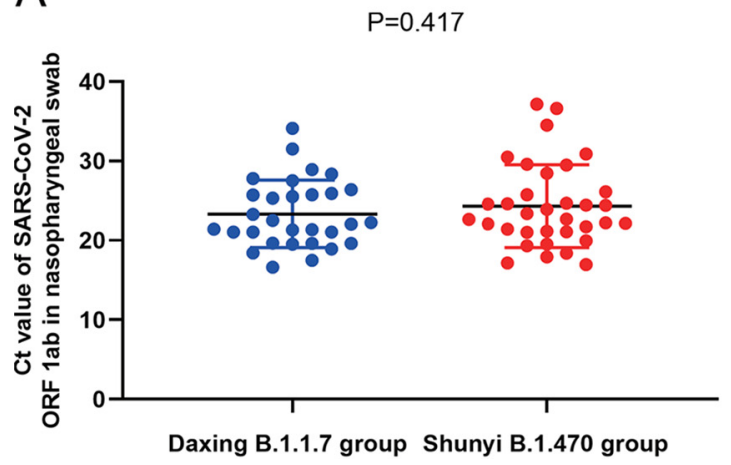

B

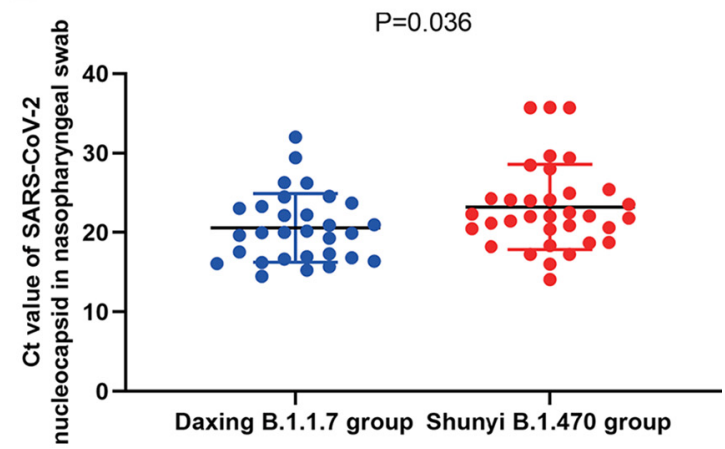

FIG 2 Scatterplot of the RT-qPCR $C_{T}$ values of the Daxing B.1.1.7 group and the Shunyi B.1.470 group. (A) $C_{T}$ values of the OFR1ab gene target. (B) $C_{T}$ values of the $\mathrm{N}$ gene target. Samples from the Daxing B.1.1.7 group are shown as red dots, while those from the Shunyi B.1.470 group are shown as blue dots. Median $C_{T}$ is indicated by a black horizontal bar. 
TABLE 5 Lowest RT-qPCR $C_{T}$ values in the two groups

\begin{tabular}{llll}
\hline & $\begin{array}{l}\text { Lowest } C_{T} \text { values for } \\
\text { Daxing B.1.1.7 group } \\
(n=33)\end{array}$ & $\begin{array}{l}\text { Lowest } C_{T} \text { values for } \\
\text { Shunyi B.1.470 group } \\
(n=41)\end{array}$ & $P$ value \\
\hline Gene target & $23.33 \pm 4.24$ & $24.31 \pm 5.21$ & 0.417 \\
\hline ORF1ab (mean \pm SD) & $20.58 \pm 4.34$ & $23.22 \pm 5.37$ & 0.036 \\
\hline
\end{tabular}

Furthermore, only two amino acid mutations in the $S$ protein were detected in the strains from the Shunyi outbreak, which suggests transmissibility lower than that of the B.1.1.7 strains.

Currently, there is no direct biological experimental evidence that can confirm the increased pathogenicity or virulence of the B.1.1.7 variant, and the clinical characteristics of B.1.1.7 variant infection have rarely been assessed. This prospective, comparative cohort study of COVID-19 cases from two COVID-19 outbreaks in Beijing implied that COVID-19 cases caused by the B.1.1.7 variant presented clinical and laboratory characteristics more serious than those of cases caused by the non-B.1.1.7 variant (lineage B.1.470).

This study has limitations. First, due to the very low morbidity of COVID-19 now in China, the sample size in the two groups of this study was relatively small. Second, we were not able to compare the clinical features between the cases infected with the B.1.1.7 variant and the cases infected with SARS-CoV-2 lineages other than B.1.470. Because during December 2020 to January 2021 only these two clustered outbreaks had taken place in Beijing, the data of these two groups were more comparable than other groups of data would be.

\section{MATERIALS AND METHODS}

Ethical approval. The study was approved by the Institutional Review Board of Beijing Ditan Hospital, Capital Medical University in Beijing (approval number JDLY2020-020-01).

Study design and recruitment of cases. This study included a total of 74 confirmed COVID-19 cases from Beijing Ditan Hospital, which were divided into the Daxing B.1.1.7 group and the Shunyi B.1.470 group. The data of all the cases from the two groups were extracted from the cloud database. The confirmed cases referred to patients with clinical features of COVID-19 and a positive RT-qPCR test for SARSCoV-2 RNA at least once in the respiratory specimens collected. The Daxing B.1.1.7 group contained a total of 33 cases, whereas the Shunyi B.1.470 group contained 41 cases. COVID-19 patients were diagnosed according to the 8th version of Diagnosis and Treatment Protocol for Novel Coronavirus Pneumonia Patients, and the clinical severity was categorized into 4 grades: mild (the clinical symptoms were mild, and there was no sign of pneumonia on imaging), moderate (fever and respiratory symptoms, imaging manifestations of pneumonia), severe (dyspnea with a respiratory rate of $>30 / \mathrm{min}$, hypoxemia with oxygen saturation of $<93 \%, \mathrm{PaO} / \mathrm{FiO} 2$ of $<300 \mathrm{~mm} \mathrm{Hg}$, or the clinical symptoms worsened gradually, and the lung imaging showed that the lesions progressed more than $50 \%$ within 24 to $48 \mathrm{~h}$ ), and critical (developed complications, including respiratory failure that needed mechanical ventilation, shock, or other organ failure that needed intensive care unit [ICU] monitoring treatment). Asymptomatic patients with no clinical symptoms but positive RT-qPCR results were also admitted to the hospital. Each patient was observed for at least 28 days. As of this study (June 18, 2021), all the patients had been discharged.

Data collection. The data of the 74 COVID-19 cases from the two groups were extracted from the cloud database. Medical record review was performed to collect patients' underlying medical conditions and symptoms at the time of diagnosis, including data on the chronology of symptom onset, history of first presentation, disease progression, past medical history, physical findings, laboratory test results, imaging results, treatment, and hospital course. In addition, epidemiological data of the patients were

TABLE 6 Risk of $C_{T}$ value of $\leq 18$ or $>18$ of $\mathrm{N}$ gene target by variant (B.1.1.7 variant infection or non-B.1.1.7 variant infection)

\begin{tabular}{lllllll}
\hline Variable & $\begin{array}{l}\text { Regression } \\
\text { coefficient }\end{array}$ & SE & $\begin{array}{l}\text { Wald Chisq } \\
\text { value }\end{array}$ & $P$ value & $\begin{array}{l}\text { Odds } \\
\text { ratio }\end{array}$ & $\begin{array}{l}95 \% \mathrm{Cl} \text { for } \\
\text { OR }\end{array}$ \\
\hline Age & -0.01 & 0.02 & 0.42 & 0.518 & 0.99 & $0.96,1.02$ \\
Group & 1.50 & 0.67 & 5.08 & 0.024 & 4.48 & $1.22,16.53$ \\
\hline
\end{tabular}


collected. Individual data were compiled into two groups of patients, those with the Daxing B.1.1.7 group and those with the Shunyi B.1.470 group, for further analyses.

Laboratory testing. Oropharyngeal swabs, nasopharyngeal swabs, or sputum specimens obtained from patients during their hospital stays were collected for RT-qPCR testing. Viral RNA was extracted directly from 200- $\mu$ l swab samples with a QIAamp viral RNA minikit (Qiagen, Germany). RT-qPCR was conducted using the novel SARS-CoV-2 nucleic acid test kit (BioGerm, Shanghai, China) with a fluorescence PCR detector following the manufacturers' instructions. A TaqMan probe-based kit was designed to detect the ORF1ab and $\mathrm{N}$ genes of SARS-CoV-2 in 1 reaction. Corresponding serum samples were tested for anti-SARS-CoV-2 antibodies using a chemiluminescence immunoassay (CLIA; Bioscience, Chongqing, China).

Whole-genome sequencing and analysis. The selected swab samples of the patients were then sent to the Chinese CDC for further whole-genome sequencing. Libraries were prepared using a Nextera XT library prep kit (Illumina, San Diego, CA, USA), and the resulting DNA libraries were sequenced on either a MiSeq or an iSeq platform (Illumina) using a 300-cycle reagent kit. Mapped assemblies were generated using the SARS-CoV-2 genome (accession number NC_045512) as a reference. Variant calling, genome alignment, and sequence illustrations were generated with CLCBio software. Whole-genome sequence alignment was conducted using the Muscle tool in MEGA (version 7.0). A neighbor-joining phylogenetic tree was constructed using MEGA (version 7.0), and the Kimura 2-parameter model with 1,000 bootstrap replicates was used. Genomic lineage designation was performed using the PANGO lineage typing method (https://cov-lineages.org/).

Statistical analysis. The statistical analyses were performed using SPSS version 24.0 (SPSS IBM, Armonk, NY, USA). From each individual patient, we entered the demographic and clinical variables. Normal continuous variables are represented by mean and standard deviation. Student's $t$ test was used to find significant differences. Nonnormally distributed continuous variables are represented by median and quartile range, and the Mann-Whitney $U$ test was used for comparison. Categorical variables are expressed as numbers and percentages, and the chi-squared test and Fisher's exact test were used to compare them. Binary logistic regression analysis was performed to analyze the risk factors for the severity of COVID-19. All tests were two-tailed, and statistical significance was defined as a $P$ value lower than 0.05 .

Data sharing. The sequence data generated in this study are made available to researchers through the GISAID database (accession no. EPI_ISL_1121993 and EPI_ISL_1122015 to 1122017).

\section{ACKNOWLEDGMENTS}

We thank all physicians who participated in the management of these COVID-19 cases. The study was funded by the National Key Research and Development Program (grant no. 2020YFC0846200 and 2020YFC0848300), National Natural Science Foundation of China (grant no. 82072295) and National Science and Technology Major Project (grant no. 2018ZX10713002).

Z.C. conceived the study, Z.C., W.X., and W.Z. designed the study, Z.C. and W.Z. maintained the database for data collection, Z.C., W.X., and W.Z. supervised the data collection, W.Z., S.C., Z.G., D.T., Y.S., G.W., X.W., Y.W., P.X., Y.X., T.Z., L.L., G.L., and J.T. interpreted the data, S.C., Z.G., and G.W. did the statistical analysis, Y.S. prepared the manuscript, Y.S., W.Z., S.C., and Z.G. wrote the manuscript, Y.S. and S.C. prepared the figures, Y.S., X.Z., S.Z., and Y.W. did the COVID-19 specimen processing and sequencing, and all authors reviewed and approved the final version of the manuscript. Z.C., W.Z., and W.X. are the guarantors.

We declare no conflicts of interest.

\section{REFERENCES}

1. Wang D, Hu B, Hu C, Zhu F, Liu X, Zhang J, Wang B, Xiang H, Cheng Z, Xiong Y, Zhao Y, Li Y, Wang X, Peng Z. 2020. Clinical characteristics of 138 hospitalized patients with 2019 novel coronavirus-infected pneumonia in Wuhan, China. JAMA 323:1061-1069. https://doi.org/10.1001/jama.2020.1585.

2. Zhu N, Zhang D, Wang W, Li X, Yang B, Song J, Zhao X, Huang B, Shi W, Lu R, Niu P, Zhan F, Ma X, Wang D, Xu W, Wu G, Gao GF, Tan W, China Novel Coronavirus Investigating and Research Team. 2020. A novel coronavirus from patients with pneumonia in China, 2019. N Engl J Med 382:727-733. https://doi.org/10.1056/NEJMoa2001017.

3. Walensky RP, Walke HT, Fauci AS. 2021. SARS-CoV-2 variants of concern in the United states-challenges and opportunities. JAMA 325:1037. https:// doi.org/10.1001/jama.2021.2294.

4. Tada T, Dcosta BM, Samanovic-Golden M, Herati RS, Cornelius A, Mulligan MJ, Landau NR. 2021. Neutralization of viruses with European, South African, and United States SARS-CoV-2 variant spike proteins by convalescent sera and BNT162b2 mRNA vaccine-elicited antibodies. bioRxiv. 2021.02.05.430003. https://doi.org/10.1101/2021.02.05.430003.
5. Fujino T, Nomoto $H$, Kutsuna $S$, Ujiie M, Suzuki T, Sato R, Fujimoto T, Kuroda M, Wakita T, Ohmagari N. 2021. Novel SARS-CoV-2 variant identified in travelers from Brazil to Japan. Emerg Infect Dis 27:1243-1245. https://doi.org/10 3201/eid2704.210138

6. Dao MH, Nguyen HT, Nguyen TV, Nguyen AH, Luong QC, Vu NHP, Pham HTT, Nguyen TNT, Thach DH, Nguyen LV, Bui LV, Nguyen HM, Huynh LKT, Nguyen LT, Cao TM, Pham QD, Nguyen TV, Phan LT. 2021. New SARS-CoV-2 variant of concern imported from the United Kingdom to Vietnam, December 2020. J Med Virol 93:2628-2630. https://doi.org/10.1002/jmv.26908.

7. Brookman S, Cook J, Zucherman M, Broughton S, Harman K, Gupta A. 2021. Effect of the new SARS-CoV-2 variant B.1.1.7 on children and young people. Lancet Child Adolesc Health 5:E9-E10. https://doi.org/ 10.1016/S2352-4642(21)00030-4.

8. Mwenda M, Saasa N, Sinyange N, Busby G, Chipimo PJ, Hendry J, Kapona O, Yingst S, Hines JZ, Minchella P, Simulundu E, Changula K, Nalubamba KS, Sawa H, Kajihara M, Yamagishi J, Kapin'a M, Kapata N, Fwoloshi S, Zulu P, Mulenga LB, Agolory S, Mukonka V, Bridges DJ. 2021. Detection of B.1.351 
SARS-CoV-2 variant strain - Zambia, December 2020. MMWR Morb Mortal Wkly Rep 70:280-282. https://doi.org/10.15585/mmwr.mm7008e2.

9. Rambaut A, Holmes EC, O'Toole Á, Hill V, McCrone JT, Ruis C, Du Plessis L, Pybus OG. 2020. A dynamic nomenclature proposal for SARS-CoV-2 lineages to assist genomic epidemiology. Nat Microbiol 5:1403-1407. https:// doi.org/10.1038/s41564-020-0770-5.

10. Rambaut A, Holmes EC, O'Toole Á, Hill V, McCrone JT, Ruis C, Du Plessis L, Pybus OG. 2021. Addendum: a dynamic nomenclature proposal for SARSCoV-2 lineages to assist genomic epidemiology. Nat Microbiol 6:415. https://doi.org/10.1038/s41564-021-00872-5.

11. Alpert $T$, Lasek-Nesselquist $E$, Brito $A F$, Valesano $A L$, Rothman J, MacKay MJ, Petrone ME, Breban MI, Watkins AE, Vogels CBF, Russell A, Kelly JP, Shudt M, Plitnick J, Schneider E, Fitzsimmons WJ, Khullar G, Metti J, Dudley JT, Nash M, Wang J, Liu C, Hui P, Muyombwe A, Downing R, Razeq J, Bart SM, Murphy S, Neal C, Laszlo E, Landry ML, Cook PW, Fauver JR, Mason CE, Lauring AS, St. George K, MacCannell DR, Grubaugh ND. 2021. Early introductions and community transmission of SARS-CoV-2 variant B.1.1.7 in the United States. medRxiv. https://doi.org/10.1101/2021.02.10.21251540

12. Eurosurveillance editorial team. 2021. Updated rapid risk assessment from ECDC on the risk related to the spread of new SARS-CoV-2 variants of concern in the EU/EEA - first update. Euro Surveill 26.
13. Shu Y, McCauley J. 2017. GISAID: global initiative on sharing all influenza data - from vision to reality. Euro Surveill 22:30494. https://doi.org/10 .2807/1560-7917.ES.2017.22.13.30494.

14. Kidd M, Richter A, Best A, Cumley N, Mirza J, Percival B, Mayhew M, Megram O, Ashford F, White T, Moles-Garcia E, Crawford L, Bosworth A, Atabani SF, Plant T, McNally A. 2021. S-variant SARS-CoV-2 lineage B1.1.7 is associated with significantly higher viral loads in samples tested by TaqPath polymerase chain reaction. J Infect Dis 223:1666-1670. https:// doi.org/10.1093/infdis/jiab082.

15. Liu K, Chen Y, Lin R, Han K. 2020. Clinical features of COVID-19 in elderly patients: a comparison with young and middle-aged patients. J Infect 80: e14-e18. https://doi.org/10.1016/j.jinf.2020.03.005.

16. Han W, Zhu M, Chen J, Zhang J, Zhu S, Li T, Cai H, Fang Q, Wei G, Liang T. 2020. Lung transplantation for elderly patients with end-stage COVID-19 pneumonia. Ann Surg 272:e33-e34. https://doi.org/10.1097/SLA.0000000000003955.

17. Armitage R, Nellums LB. 2020. COVID-19 and the consequences of isolating the elderly. Lancet Public Health 5:e256. https://doi.org/10 .1016/S2468-2667(20)30061-X.

18. Petretto DR, Pili R. 2020. Ageing and COVID-19: what is the role for elderly people? Geriatrics 5:25. https://doi.org/10.3390/geriatrics5020025. 